\title{
One health: The interface between veterinary and human health
}

\author{
Kshitiz Shrestha ${ }^{1}$, Krishna Prasad Acharya ${ }^{2}$ and Sujan Shrestha ${ }^{3}$
}

1. Department of Veterinary Medicine, Kasetsart University, Faculty of Veterinary Medicine, Bangkok, Thailand; 2. Regional Veterinary Laboratory, Pokhara, Nepal; 3. National Academy of Medical Science, Bir Hospital, Kathmandu, Nepal.

Corresponding author: Kshitiz Shrestha, e-mail: shresthakshtz@gmail.com

Co-authors: KPA: kriaasedu@gmail.com, SS: ksh.massey@gmail.com

Received: 12-12-2017, Accepted: 08-01-2018, Published online: 29-01-2017

doi: 10.14202/IJOH.2018.8-14 How to cite this article: Shrestha K, Acharya KP, Shrestha S. One health: The interface between veterinary and human health. Int J One Health 2018;4:8-14.

\begin{abstract}
One Health is an emerging global key concept integrating human and animal health through international research and policy. The complex relationships between the human and animal have resulted in a human-animal-environment interface since prehistorical times. The people, animals, plants, and the environment are so intrinsically linked that prevention of risks and the mitigation of effects of crises that originate at the interface between humans, animals, and their environments can only improve health and wellbeing. The "One Health" approach has been successfully implemented in numerous projects around the world. The containment of pandemic threats such as avian influenza and severe acute respiratory syndrome within months of outbreak are few examples of successful applications of the One Health paradigm. The paper begins with a brief overview of the human-animal interface and continues with the socio-economic and public health impact caused by various zoonotic diseases such as Middle East respiratory syndrome, Influenza, and Ebola virus. This is followed by the role of "One Health" to deal the global problem by the global solution. It emphasizes the interdisciplinary collaboration, training for health professionals and institutional support to minimize global health threats due to infectious diseases. The broad definition of the concept is supposed to lead multiple interpretations that impede the effective implementation of One Health approach within veterinary profession, within the medical profession, by wildlife specialists and by environmentalists, while on the other side, it gives a value of interdisciplinary collaboration for reducing threats in human-animal-environment interface.
\end{abstract}

Keywords: emerging infectious diseases, one health, viral zoonoses.

\section{Introduction}

Humans and microbes are engaged in a moral, self-interested, coevolutionary struggle [1,2]. The inextricable connectivity between animals, humans, and the environment has been recognized for centuries. Diamond and Ford [3] has put forth: "Questions of the animal origins of human disease lie behind the broadest pattern of human history and behind some of the most important issues of human health today." The complex relationships between the human and animal have resulted in a human-animal interface since prehistoricaltimes [4].

Research findings have implicated wildlife as an important "zoonotic pool" of novel pathogens, and the domestic animals act as amplifiers of pathogens emerging from the wild [3]. A study has conclusively shown the positive correlation between time since its domestication and the number of infectious diseases (and parasites) shared between domesticated animals and humans $(\mathrm{p}<0.05)$. Therefore, domestic animals

Copyright: Shrestha, et al. This article is an open access article distributed under the terms of the Creative Commons Attribution 4.0 International License (http://creativecommons.org/licenses/ by/4.0/), which permits unrestricted use, distribution, and reproduction in any medium, provided you give appropriate credit to the original author(s) and the source, provide a link to the Creative Commons license, and indicate if changes were made. The Creative Commons Public Domain Dedication waiver (http:// creativecommons.org/ publicdomain/zero/1.0/) applies to the data made available in this article, unless otherwise stated. are also important in influencing the human infectious disease transmission cycle.

Diseases and/or infections that are naturally "transmissible from vertebrate animals to man" are classified as a zoonosis [4]. According to recent definition by the World Health Organization (WHO), any disease or infection that is naturally transmissible from vertebrate animals to humans and vice versa is classified as a zoonosis [5]. Zoonoses involve bacteria (salmonellosis, plague, anthrax, and leptospirosis), parasites (taeniasis, hydatidosis, and toxoplasmosis), viruses (rabies, Japanese encephalitis, avian influenza, Nipah, severe acute respiratory syndrome [SARS], and avian influenza), and unconventional agents (bovine spongiform encephalopathy). Some examples of zoonotic pathogens for which ruminants are an important reservoir are shiga toxin producing Escherichia coli $\mathrm{O} 157$ and $\mathrm{O} 26$, new variant Creutzfeldt-Jakob disease/bovine spongiform encephalitis (BSE), campylobacteriosis, salmonellosis, Q fever, leptospirosis. Other terms used to define the source of infection and the directions of transmission are as follows:

- Anthropozoonoses: Zoonoses maintained in nature by animals and transmissible to humans (e.g., rabies and brucellosis).

- Zooanthroponoses: Zoonoses maintained by humans but transmissible to other vertebrates (e.g., amebiasis to dogs and tuberculosis). 
The different opinions on the definition have led confusion among scientists. Therefore, WHO/FAO expert committee decided to abandon these two terms and recommended "zoonoses" as "diseases and infections which are naturally transmitted between vertebrate animals and man"[6].

The world has undergone a political revolution, rapid industrial development, and unprecedented growth of primary industries and population that has increased the human, animal, and wildlife interactions at close proximity. The changes also referred as 5 T's: Trade, transport, travel, tourism, and terrorism have opened the area for the spillover of epidemic, endemic, and pandemic zoonotic diseases $[2,7,8]$. Understanding this versatile human-animal interface is crucial for characterizing the permanent yet continuously evolving risks of cross-species transmission of pathogens between animals and humans.

The epidemiological triad is an epidemiological model of disease causation which involves an agent, a susceptible host, and an environment. Elimination of vectors that may convey agent to the host may prevent disease, but it is just the tip of the iceberg [9]. Causation of diseases includes a web of several factors that change the probability of disease occurrence. The factors are biologic, genetic, ecologic, climatic, anthropogenic, and socioeconomic [10].

Recent studies have indicated that around twothirds of the approximately 1500 agents of human infectious disease are zoonoses, 175 are considered to be "emerging," and in the important group of emerging infectious diseases, over three quarters are zoonoses [11]. There are various emerging and reemerging infections. The incidence or a spread of a pathogen into new areas or a new host species is called "disease emergence" [8]. Yet, a majority of zoonoses are not prioritized by health systems and are labeled as "neglected" or "endemic" [12-14]. Newly emerging infections are those that have not previously been recognized in humans. Reemerging and resurging infections are those that existed in the past but are now rapidly increasing either in incidence or in geographical or human host range. Deliberately emerging microbes are those that have been developed by man, usually for nefarious use.

Wildlife originated zoonoses have been the most global threat ofall emerging infectious diseases $[15,16]$. Zoonoses caused by viruses are more of a public health threat and are a cause for global concern. There are several examples that justify that viral zoonotic diseases have shaped the course of human civilization. Some examples are as follows: The "Black death" that was spread by rats in the middle ages, "Spanish flu" which was linked to influenza strains in birds [17], and human sleeping sickness linked to unrestricted cattle restocking [18]. Diseases such as influenza (avian and swine flu), SARS, and Nipah virus (NiV) have afflicted the planet over recent times and the viruses are being detected in new places which had never been recorded before. The most recent outbreak of Zika virus in Latin America [19] is an example.

Many of the zoonoses are often highly transmissible and spread rapidly (occasionally causing global pandemics) and can be fatal which has raised a great deal of attention globally. For the successful zoonotic transmission, pathogens are transmitted through only animals or only humans or both. The progression of pathogens from an animal into humans can be described in five stages [20].

Stage 1: Pathogenic agent that is specific to certain host species and that has not been detected in humans under natural conditions. Example: Most malarial plasmodia.

Stage 2: Pathogens that are transmitted to humans from animals ("primary infection") under natural conditions but not between humans ("secondary infection"). Example: Anthrax and tularemia bacilli and Nipah, rabies, and West Nile viruses.

Stage 3: Pathogens that can undergo few cycles of secondary transmission and may cause a limited outbreak. Examples: Ebola, Marburg, and monkeypox viruses.

Stage 4: Diseases that have a natural (sylvatic) cycle of infecting humans by primary transmission. Example: Chagas' disease and yellow fever. The disease also can undergo long sequences of secondary transmission between humans causing a persistent outbreak. Example: Dengue fever in forested areas of West Africa and Southeast Asia (SEA), influenza A, cholera, typhus, and West African sleeping sickness.

Stage 5: Pathogens that are exclusive to humans. Example: The agents causing falciparum malaria, measles, mumps, rubella, smallpox, and syphilis.

Another noteworthy point is the existence of species barrier to pathogen transfer which can be attributed to the phylogenetic distance. The probability-per-unit-time (p) of infection of a new host species increases with the availability of the existing donor host, with the fraction of the existing host population infected, with the frequency of "encounters" between them, with the opportunities for transmission through vectors between them, and with the probability of transmission per encounter [20]. While p decreases when the phylogenetic distance between the existing host and new host is increased and $p$ also varies with microbe's characteristics. Close phylogenetic relationship of chimpanzees' to humans has resulted in numerous diseases such as AIDS and hepatitis B in humans, despite their low abundance and less frequent encounters with humans. Whereas, plague and typhus are established diseases acquired from rodents due to their high abundance and dwellings around human households. For example, trypanosomes and flaviviruses infect a wider taxonomic range of hosts unlike plasmodia and simian foamy viruses. The transition from Stage 1 to Stage 2 indicates that most animal pathogens are not transmitted to humans rather viruses 
such as Nipah and SARS are acquired by humans from intermediate animal hosts that frequently encounter humans. The transmission of rabies directly to humans from bats is possible when they bite humans. Stage 2 and 3 virulent pathogens such as anthrax and Marburg agents can have a global impact if they made the transition to Stage 4 or 5. The modern developments have facilitated more efficient transmission of pathogens between humans such as blood transfusion (hepatitis C), the commercial bushmeat trade (retroviruses), industrial food production (BSE), international travel (cholera), intravenous drug use (human immunodeficiency virus [HIV]), vaccine production (simian virus), and susceptible pools of the elderly, antibiotic-treated, immunosuppressed patients [21].

\section{Impact of Viral Zoonoses}

Zoonoses have proven to be a significant public health problem not to mention the explicit socioeconomic impact it exerts. It is estimated that around 2.7 million human deaths and around 2.5 billion cases of human illness a year are caused due to 56 zoonoses [22]. The direct cost of outbreaks over the last decade is estimated by the World Bank to be more than US \$20 billion which balloons to US\$200 billion when indirect costs to economies are considered [23]. Viral infections significant to human health (Table-1) [25] are ever expanding with the emergence of novel viruses such as SARS coronavirus $(\mathrm{CoV})$, H1N1 influenza virus, and Ebola virus. Viral zoonotic diseases have a global impact in terms of morbidity and mortality. Economic losses from BSE in the UK totaled the US $\$ 7$ billion, SARS in East Asia and Canada between 40 and 50 billion and highly pathogenic avian influenza in East Asia cost the livestock sector $\$ 10$ billion $[21,23]$. This also highlights that zoonotic disease is not just an issue for developing countries.

\section{Middle East respiratory syndrome (MERS)}

This novel CoV causes a severe lower respiratory illness that was first reported in Saudi Arabia in 2012 [26]. It is phylogenetically related to bat CoVs, but camels act as intermediate hosts to spread into humans. It has since spread to several other countries around the world. In a recent report, more than 1340 laboratory-confirmed human cases of MERS-CoV infection have been reported [25]. The affected age group ranges from 9 months to 94 years, and $64 \%$ of cases have been males infected with MERS-CoV who develop severe acute respiratory illness, including fever, cough, and shortness of breath leading to death.

Recently in May 2015, the Republic of Korea reported an outbreak of MERS [27]. A total of 182 confirmed cases of MERS and 32 deaths had been reported by the end of June 2015. This outbreak is the largest known outside the Arabian Peninsula. Similarly, China and Thailand have also reported cases of MERS, and hence, the threat continues.

\section{Influenza}

Influenza virus emerged after a repeated exchange of genes from a "zoonotic pool" of wildlife [8]. Studies have identified non-human primate as potential reservoirs of avian influenza from which HIV types 1 and 2 originated [28]. Influenza viruses are segmented, negative sense, single-stranded, RNA viruses classified within the family Orthomyxoviridae. Influenza A viruses have the widest host range with many subtypes identified based on the antigenic characteristics of the glycoproteins hemagglutinin (16 subtypes of HA) and neuraminidase (9 subtypes of NA) [29]. In the past 100 years, five influenza pandemics have occurred due to the emergence of a new subtype of the influenza virus. The first influenza virus outbreak believed to be due to a human-adapted avian influenza was in 1918 and killed more people in a single year than the bubonic plague [30]. It is reported that the influenza epidemic of 1918-1919 killed nearly 100 million people worldwide [31].

The first pandemic of the century - SARS occurred in 2003 followed by avian influenza [32]. SARS caused by SARS CoV originated from civet cats and spread globally in a very short span of time. A novel H1N1 human-swine-avian reassortant virus caused a pandemic threat in 2009 [33]. The WHO classed the spread of swine flu as a global pandemic [34].

Since 2003, more than 780 clinical cases of H5N1 influenza infection have been reported in humans predominating children and young adults and the infection threat persists [35]. This virus is now endemic

Table. 1: Selected viral zoonotic diseases since 1975 (Adapted from [24]).

\begin{tabular}{|c|c|c|c|}
\hline \multirow[t]{2}{*}{ Emerging disease } & \multirow[t]{2}{*}{ Year identified } & \multicolumn{2}{|c|}{ Estimated global impact } \\
\hline & & Cases & Deaths \\
\hline Ebola virus disease & 1976 & 19568 & 7653 \\
\hline $\begin{array}{l}\text { Human Immunodeficiency virus/acquired immune deficiency } \\
\text { syndrome (HIV/AIDS) }\end{array}$ & 1981 & 78 million & 39 million \\
\hline Variant Creutzfeldt-Jakob disease (vCJD or "mad cow disease") & 1996 & 229 & 229 \\
\hline H5N1 influenza ("bird flu") & 1997 & $668^{*}$ & $393 *$ \\
\hline Severe acute respiratory syndrome (SARS) & 2003 & 8096 & 774 \\
\hline H1N1 (2009) influenza ("swine flu") & 2009 & Unknown & $>284,500$ \\
\hline Middle East respiratory syndrome (MERS) & 2012 & 699 & 209 \\
\hline H7N9 influenza ("bird flu") & 2013 & 463 & 175 \\
\hline
\end{tabular}

Cases and deaths reflect the cumulative number of cases and deaths (as of October 17, 2014). *Indicates cumulative cases and deaths from 2003 to present 
among birds and poultry populations in Eurasia. The sporadic transmission of this virus to humans provides opportunities for further evolution into a novel strain that can efficiently transmit from human to human, which would create a pandemic potential.

The WHO has described the potential threat from $\mathrm{H} 5 \mathrm{~N} 1$ as a "public health crisis" [36]. A total of 571 human cases of avian influenza A (H7N9) virus infection, including 212 deaths, have been reported to the WHO until February 23, 2015. The H7N9 pandemic has not only lead to significant human mortality and morbidity but also decline of global GDP (damages of US\$3 trillion) up to 5\% according to the World Bank [37].

\section{Ebola virus}

Fruit bats have been implicated as the potential reservoir of Ebola virus [38]. Ebola virus is a non-segmented, negative-sense, single-stranded RNA virus that resembles rhabdoviruses and paramyxoviruses. It was first recognized in 1976 when two outbreaks occurred in Zaire and Sudan [39]. It is considered one of the most virulent pathogens in humans.

Brierley, Vonhof [40] has identified West Africa as the highest risk hotspot for zoonotic bat viruses and this area has observed the largest scale outbreak of Ebola virus disease till date. It is evident that areas having large and increasing populations of both humans and livestock are at a higher risk for zoonotic diseases.

The case fatality rate has been reported to be as high as $70 \%$ in the $2014-2015$ Ebola (Zaire species) epidemic in West Africa [41]. This epidemic has not only been the first to occur but also the largest outbreak so far. This virus caused several hundred cases and mortality in 1995 in Kikwit, Democratic Republic of the Congo. The Ebola outbreak began in the West African nation of Guinea in late 2013 and subsequently spread to Liberia, Sierra Leone, Nigeria, Senegal, and Mali. The cumulative number of probable, suspected, and laboratory-confirmed cases attributed to Ebola virus infection until May 31, 2015, is 27,181, including 11,162 deaths [42]. According to the same report, approximately $60 \%$ of over 860 infected healthcare workers have lost their lives during the same epidemic. The magnitude of the outbreak has probably been underestimateddue in part to the patients being cared for outside of the hospital settings.

\section{NiV infection}

$\mathrm{NiV}$ is a newly discovered non-segmented RNA virus of the paramyxovirus family. The NiV first emerged in Malaysia in 1998 during an outbreak which caused more than 100 human deaths [43]. Initially, the cause was considered to be Japanese encephalitis and then Hendra virus, but later it was identified as NiV.

Fruit bats (Pteropus spp.) are the reservoirs of this virus that was first transmitted to domestic pigs and NiV was extracted in the fruit remaining dropped by these bats in Malaysia [44]. Malaysia has been producing pigs for several decades; however, the movement of bats and their densities were not as pronounced around pig farms until the late 1990s [45]. Anthropogenic activity such as intensified farming, establishing pig sties combined with orcharding close to fruit bat habitats, wildfires in Sumatra forest, and El Nino southern oscillation events are the proposed causation for the migration of fruit bats from Sumatra to Peninsular Malaysia. This led to the introduction of the virus into the index farm region. However, another study showed that the Sumatran forest fires have been associated with coral die-offs as well as the regular haze events in Malaysia [46].

$\mathrm{NiV}$ emergence is linked to farming intensification and environmental change. NiV infection was also confirmed in Bangladesh and India between 2001 and 2005 [47]. Although NiV antibodies were found in a serological survey of Pteropus spp., fruit bats, the pigs, and other animals were not found to be infected $[48,49]$. Human-to-human transmission has not been documented.

\section{Rabies}

Rabies has been known since antiquity and draws huge concern, especially in regions with unvaccinated dogs. Rabies has been endemic in Thailand and much of Asia for many years, and sylvatic and urban cycles have maintained its transmission. There is also a possibility of a spillover of rabies virus from dogs to wildlife and vice versa. The dog is, however, the main reservoir and vector with wildlife playing a minor role [37]. The complete range of bat rabies is not demonstrated. Nearly 70,000 people die of rabies every year [50], mostly in developing countries of Africa and Asia. Approximately 21,000-24,000 people $(45 \%$ of the worldwide number of cases) die of rabies in SEA [51], of which India accounts for more deaths than any other country.

\section{Role of One Health - Global Problems Require Global Solutions}

The One Health approach recognizes that the human, animal (including livestock, wildlife, and other animals), and environmental health are inextricably linked, and it is a widely accepted prism through which governments, nongovernmental organizations, and practitioners view human health [52]. This approach seeks to improve the health and well-being of humans, animals, and the environment through innovative, intersectoral, and interprogrammatic development. There are a variety of definitions of the One Health. Zinsstag, Meisser [53] state that "One Health is anything that adds value to the health of animals and humans, or economic savings, not achievable without the cooperation of the two medicines. It should just become normal that doctors and veterinarians work together as closely as possible." The One Health Commission defines One Health differently 
stating that "One Health is the collaborative effort of multiple health science professions, together with their related disciplines and institutions - working locally, nationally, and globally - to attain optimal health for people, domestic animals, wildlife, plants, and our environment" [54].

One Health encourages coordination, communication, data sharing, and joint efforts between the involved parties. It is a worldwide strategy and it aims to integrate policy interventions across multiple sectors and disciplines to identify potential public health risks related to infectious disease. It helps in the development of new ways of tackling the various oncoming challenges such as food security and safety, emerging and endemic zoonotic diseases, antimicrobial and drug resistance, climate change, and human-animal bond. This helps to undertake simultaneous and holistic approach to yield significantly larger health benefits instead of targeting an isolated area. Since it is a cross-sectoral and multidisciplinary, it involves anthropology, bioinformatics, ecology, economics, epidemiology, genetics, mathematics, medical (clinical), microbiology, meteorology, political sciences, social sciences, and veterinary (clinical).

The people, animals, plants, and the environment are so intrinsically linked that prevention of risks and the mitigation of effects of crises that originate at the interface between humans, animals, and their environments can only improve health and well-being. Therefore, a collaborative approach among the multidisciplinary team is required to design an effective intervention strategy to promote human health.

The One Health concept is gaining widespread acceptance. There are several successful applications of One Health paradigm. "One Health Task Force" is one way of operationalisation of "One Health" and this kind of logical approach to combat zoonoses may need to be expanded globally [55]. The containment of pandemic threats such as avian influenza and SARS within months of outbreak through international solidarity and mutual cooperation [32] indicates the importance of One Health.

In 2006, the Health for Animals and Livelihood Improvement [56] project was initiated in rural Tanzania. This project is assessing the impact of zoonotic disease on the health of people living in a water-limited ecosystem, simultaneously investigating the medical, ecological, socioeconomic, and policy issues. Rabies and Rift Valley fever are important zoonotic diseases present in wildlife, domestic animals, and people in Tanzania [57]. The multilevel approach of this project includes testing of wildlife, livestock, and their water sources for potential zoonotic pathogens; testing water quality and their use; assessing wildlife demography; evaluating disease impacts on people; village economies; introducing disease detection and training programs; and developing health and environmental policies. Therefore, several issues that interact together are brought together in a common framework instead of dealing with just a single issue.
In 2011, a memorandum of understanding was signed to promote increased One Health collaboration between the World Small Animal Veterinary Association and the OIE [58]. These partner organizations have encouraged the use of public-private partnerships to implement appropriate prevention and control methods for rabies. They have provided support to establish regional vaccine banks in close collaboration with major donor organizations to support the fight against rabies. On December 10, 2015, the WHO and the World Organization for Animal Health, in collaboration with the UN Food and Agriculture Organization and the Global Alliance for the Control of Rabies, launched a global framework to eliminate rabies by 2030 [59]. This initiative marks the first time that the human and animal health sectors have come together to adopt a common strategy to tackle this disease. In the past 5 years, Tanzania, South Africa, Bangladesh, and the Philippines have proven that elimination of rabies is feasible and affordable. Therefore, One Health coordinates between human and animal health, assists in support from donors and stakeholders in the public and private sectors, and engages the community to achieve the goals.

There are several health problems and in many areas of the world where One Health approach can be implemented. Antimicrobial resistance has dominated the health concern because of its emergence and importance globally. Other examples are parasitic diseases, zoonotic diseases, and vector-borne diseases such as malaria, Japanese encephalitis, and dengue. For the prevention and control of such diseases requires multisectoral action for which One Health approach can be the best suitable action.

\section{Challenges to the Future}

There have been concerns over the effective implementation of One Health within veterinary profession [53,60-62], within the medical profession [63], by wildlife specialists [64], and by environmentalists [65]. The strikingly broad definition obviously allows multiple interpretations of the concept. It gives the general idea of collaboration and convergence; nevertheless, it does not engage with the specifics of how this should take place [66]. One Health has also primarily been a method to "rebrand" or "advertise" their own work to gain popularity. Furthermore, Häsler, Gilbert [62] reported that health professionals from human health sector are not engaged with One Health, whereas those working in animal and environmental health are interested in the concept.

Shortage of collaborative programs, insufficient environmental training for health professionals, and a lack of institutional support impede progress to address global health and sustainability challenges [67]. Incorporating One Health into academic schedule could lead a significant impact on creating awareness and attitudes toward public health and safety. 


\section{Conclusion}

Humans have had the luxury of forgetting about the catastrophic effects of zoonotic diseases that have occurred in the past. There has definitely been an upsurge of disease emergence particularly zoonotic diseases in the past few decades. It is critical that we do not disregard the possible disease outbreaks and that we combat emerging diseases in a systematic way. Provided the fact that zoonoses have a huge impact on public health as well as the animals and wildlife, employing a systematic One Health approach is important. Finally, it gives a value of interdisciplinary collaboration for reducing threats to global health from infectious diseases.

\section{Authors' Contributions}

All authors contributed in writing different sections, to review and finalizing the article. All authors read and approved the final manuscript.

\section{Acknowledgments}

Acknowledgment to Dr. Magda Dunowska at Massey University, New Zealand for her feedback and ideas.

\section{References}

1. Weiss RA, McMichael AJ. Social and environmental risk factors in the emergence of infectious diseases. Nat Med 2004; 10:S70-6.

2. McMichael AJ. Environmental and social influences on emerging infectious diseases: Past, present and future. Philos Trans R Soc B Biol Sci 2004;359:1049-58.

3. Diamond J, Ford LE. Guns, germs, and steel: the fates of human societies. Perspect Biol Med 2000;43:609.

4. Mackenzie JS, Jeggo M, Daszak P, Richt JA. One Health: The Human-Animal-Environment Interfaces in Emerging Infectious Diseases. Heidelberg: Springer; 2013.

5. Morand S, McIntyre KM, Baylis M. Domesticated animals and human infectious diseases of zoonotic origins: Domestication time matters. Infect Genet Evol 2014;24:76-81.

6. Acha PN, Szyfres B. Zoonoses and Communicable Diseases Common to Man and Animals: Parasitic Zoonoses. Vol. 3. Washington, DC: Pan American Health Organisation; 2003.

7. World Health Organization. Zoonoses and the HumanAnimal-Ecosystems Interface. Available from: http://www. who.int/zoonoses/en. [Last cited on 2015 Dec 05].

8. Hubálek Z. Emerging human infectious diseases: Anthroponoses, zoonoses, and sapronoses. Emerg Infect Dis 2003;9:403.

9. Harper K, Armelagos G. The changing disease-scape in the third epidemiological transition. Int J Environ Res Public Health 2010;7:675-97.

10. Morse SS. Factors in the emergence of infectious diseases. Emerg Infect Dis 1995;1:7-15.

11. Krieger N. Epidemiology and the web of causation: Has anyone seen the spider? Soc Sci Med 1994;39:887-903.

12. Gebreyes WA, Dupouy-Camet J, Newport MJ, Oliveira CJ, Schlesinger LS, Saif YM, et al. The global one health paradigm: Challenges and opportunities for tackling infectious diseases at the human, animal, and environment interface in low-resource settings. PLoS Negl Trop Dis 2014;8:e3257.

13. Taylor LH, Latham SM, Mark E. Risk factors for human disease emergence. Philosophical transactions of the royal society of London. Series B Biol Sci 2001;356:983-9.

14. World Health Organization. Strategic and Technical Meeting on Intensified Control of Neglected Tropical Diseases: A Renewed Effort to Combat Entrenched Communicable Diseases of the Poor. Berlin: Report of an International Workshop; 2006.

15. World Health Organization. The Control of Neglected Zoonotic Diseases: A Route to Poverty Alleviation: Report of a Joint WH; 2006.

16. World Health Organization. Intensified Control of Neglected Diseases: Report of an International Workshop. Berlin: WHO; 2004.

17. Jones KE, Patel NG, Levy MA, Storeygard A, Balk D, Gittleman JL, et al. Global trends in emerging infectious diseases. Nature 2008;451:990-3.

18. Woolhouse ME, Gowtage-Sequeria S. Host range and emerging and reemerging pathogens. In: Ending the War Metaphor: The Changing Agenda for Unraveling the Host-Microbe Relationship-Workshop Summary, National Academies Press; 2006.

19. Taubenberger JK, Reid AH, Lourens RM, Wang R, Jin G, Fanning TG, et al. Characterization of the 1918 influenza virus polymerase genes. Nature 2005;437:889-93.

20. Fèvre E, Coleman $\mathrm{P}$, Odiit $\mathrm{M}$, Magona J, Welburn S, Woolhouse M, et al. The origins of a new Trypanosoma brucei rhodesiense sleeping sickness outbreak in eastern Uganda. Lancet 2001;358:625-8.

21. Morens DM, Folkers GK, Fauci AS. The challenge of emerging and re-emerging infectious diseases. Nature 2004;430:242-9.

22. McNeil DG Jr. Zika Virus, a Mosquito-Borne Infection, May Threaten Brazil's Newborns. New York: New York Times; 2015.

23. Wolfe ND, Dunavan CP, Diamond J. Origins of major human infectious diseases. Nature 2007;447:279-83.

24. Grace D, Mutua F, Ochungo P, Kruska R, Jones K, Brierley L, et al. Mapping of Poverty and Likely Zoonoses Hotspots; 2012.

25. Foundation TH. The U.S. Government and Global Emerging Infectious Disease Preparedness and Response; 2014. Available from: http://www.kff.org/global-health-policy/ fact-sheet/the-u-s-government-global-emerging-infectious-disease-preparedness-and-response. [Last accessed on 2015 Jun 28].

26. WHO. Global Burden of Disease Report 2004 Update, 2008, Accessed; 2013.

27. Hardy AT. The World Turned Upside Down: The Complex Partnership between China and Latin America. Vol. 34. Singapore: World Scientific; 2013.

28. Assiri A, Al-Tawfiq JA, Al-Rabeeah AA. Epidemiological, demographic, and clinical characteristics of 47 cases of Middle East respiratory syndrome coronavirus disease from Saudi Arabia: A descriptive study. Lancet Infect Dis 2013;13:752-s61.

29. World Health Organization. Middle East Respiratory Syndrome Coronavirus (MERS-CoV): Summary of Current Situation, Literature Update and Risk Assessment-as of 5 February 2015. World Health Organization; 2015.

30. World Health Organization. MERS-CoV in Republic of Korea at a Glance. World Health Organization; 2015

31. Gao F, Bailes E, Robertson DL, Chen YL, Rodenburg CM, Michael SF, et al. Origin of HIV-1 in the chimpanzee pan troglodytes troglodytes. Nature 1999;397:436-41.

32. Alexander DJ. An overview of the epidemiology of avian influenza. Vaccine 2007;25:5637-44.

33. Ungchusak K, Auewarakul P, Dowell SF, Kitphati R, Auwanit W, Puthavathana P, et al. Probable person-to-person transmission of avian influenza A (H5N1). N Engl J Med 2005;352:333-40.

34. Osterholm MT. Preparing for the next pandemic. New Engl J Med 2005;352:1839-42.

35. Heymann DL, Rodier G. Global surveillance, national surveillance, and SARS. Emerg Infect Dis 2004;10:173-5.

36. Pawaiya R, Dhama K, Mahendran M, Tripathi B. Swine flu 
and the current influenza A (H1N1) pandemic in humans: A review. Indian J Vet Pathol 2009;33:1-17.

37. BBC. Swine Flu: Country by Country; 2015. Available from: http://www.news.bbc.co.uk/2/hi/uk/8083179.stm. [Last cited on 2015 Dec 11].

38. Capua I, Marangon S. Control of avian influenza in poultry. Emerging Infect Dis 2006;12:1319.

39. WHO Risk Assessment of Human Infections with Avian Influenza A(H7N9) Virus; 2015. Available from: http:// www.who.int/influenza/human_animal_interface/ influenza h7n9/RiskAssessment $\overline{\mathrm{H}} 7 \mathrm{~N} 9 \quad 2 \overline{3} \mathrm{Feb} 20115$. pdf?ua $=1$. [Last cited on 2015 Jun 28].

40. Baize S, Pannetier D, Oestereich L, Rieger T, Koivogui L, Magassouba N, et al. Emergence of Zaire Ebola virus disease in Guinea. New Engl J Med 2014;371:1418-25.

41. Muyembe-Tamfum JJ, Mulangu S, Masumu J, Kayembe JM, Kemp A, Paweska JT, et al. Ebola virus outbreaks in Africa: Past and present. Onderstepoort J Vet Res 2012;79:6-13.

42. Brierley L, Vonhof MJ, Olival KJ, Daszak P, Jones KE. Quantifying global drivers of zoonotic bat viruses: A process-based perspective. Am Nat 2016;187:E53-64.

43. Team WE. Ebola virus disease in West Africa-the first 9 months of the epidemic and forward projections. N Engl J Med 2014;371:1481-95.

44. World Health Organization. Ebola Situation Report-3 June 2015. Geneva: WHO; 2015.

45. Chua K, Bellini WJ, Rota PA, Harcourt BH, Tamin A, Lam SK, et al. Nipah virus: A recently emergent deadly paramyxovirus. Science 2000;288:1432-5.

46. Mohd NM, Gan C, Ong B. Nipah virus infection of pigs in peninsular Malaysia. Rev Sci Tech 2000;19:160-5.

47. Chua KB. Nipah virus outbreak in Malaysia. J Clin Virol 2003;26:265-75.

48. Abram NJ, Gagan MK, McCulloch MT, Chappell J, Hantoro WS. Coral reef death during the 1997 Indian Ocean dipole linked to Indonesian wildfires. Science 2003;301:952-5.

49. Field HE. Bats and emerging zoonoses: henipaviruses and SARS. Zoonoses Public Health 2009;56:278-84.

50. Daszak P, Plowright RK, Epstein JH, Pulliam J, Rahman SA. The emergence of Nipah and Hendra virus: Pathogen dynamics across a wildlife-livestock-human continuum. Disease Ecology: Community Structure and Pathogen Dynamics. Cary, NC: Oxford University Press; 2006. p. 186-201.

51. Hsu VP, Hossain MJ, Parashar UD, Ali MM, Ksiazek TG, Kuzmin I, et al. Nipah virus encephalitis reemergence, Bangladesh. Emerg Infect Dis 2004;10:2082-7.

52. Hankins DG, Rosekrans JA. Overview, prevention, and treatment of rabies. In: Mayo Clinic Proceedings. Elsevier; 2004.
53. Gongal G, Wright AE. Human rabies in the WHO Southeast Asia Region: Forward Steps for elimination. Adv Prev Med 2011;2011:383870.

54. Food and Agriculture Organization, World Organization for Animal Health. Contributing To One World, One Health: A Strategic Framework for Reducing Risks of Infectious Diseases at the Animal-Human-Ecosystems Interface; 2008.

55. Zinsstag J, Meisser A, Schelling E, Bonfoh B, Tanner M. From two medicines to one medicine to one health and beyond. In: $1^{\text {st }}$ African One Health Conference, Johannesburg July; 2011.

56. One Health Commission. World Health Through Collaboration; 2015. Available from: https://www.onehealthcommission.org/en/why_one_health/rationale. [Last cited on 2015 Dec 12].

57. Mazet JA, Clifford DL, Coppolillo PB, Deolalikar AB, Erickson JD, Kazwala RR. A "one health" approach to address emerging zoonoses: the HALI project in Tanzania. PLoS Med 2009;6:e1000190.

58. Enserink M. Initiative aims to merge animal and human health science to benefit both. Science 2007;316:1553.

59. Wolking D. Health for Animals and Livelihood Improvement (HALI) Project; 2013. Available from: https://www.haliproject.wordpress.com. [Last cited on 2015 Dec 19].

60. Kilonzo B, Komba E. The current epidemiology and control of trypanosomiasis and other zoonoses in Tanzania. Cent Afr J Med 1993;39:10-20.

61. Gibbs EP. The evolution of one health: A decade of progress and challenges for the future. Vet Record 2014;174:85-91.

62. Time to eliminate rabies. Lancet 2015;386:2446.

63. Okello AL, Gibbs EP, Vandersmissen A, Welburn SC. One health and the neglected zoonoses: turning rhetoric into reality. Vet Rec 2011;169:281-5.

64. Gibbs SE, Gibbs EP. The historical, present, and future role of veterinarians in one health. In: One Health: The HumanAnimal-Environment Interfaces in Emerging Infectious Diseases. New York: Springer; 2013. p. 31-47.

65. Häsler B, Gilbert W, Jones BA, Pfeiffer DU, Rushton J, Otte MJ, et al. The economic value of one health in relation to the mitigation of zoonotic disease risks. In: One Health: The Human-Animal-Environment Interfaces in Emerging Infectious Diseases. New York: Springer; 2013. p. 127-51.

66. Atlas RM. One health: Its origins and future. In: One Health: The Human-Animal-Environment Interfaces in Emerging Infectious Diseases. New York: Springer; 2013. p. 1-13.

67. Rostal MK, Olival KJ, Loh EH, Karesh WB. Wildlife: The need to better understand the linkages. In: One Health: The Human-Animal-Environment Interfaces in Emerging Infectious Diseases. New York: Springer; 2013. p. 101-25. 